extracting with sufficiently strong acid, the total amount of ascorbic acid is obtained. The fact that practically none of the ascorbic acid is recovered by acidifying or heating an aqueous extract indicates that nearly all the apparent increase on cooking is due to the inactivation of the enzyme. The slight increase on heating the aqueous extract may or may not be due to the liberation of bound ascorbic acid. I do not regard it as evidence of the existence of an ascorbic acid ester in natural foodstuffs.

N.Y. State Agricultural Experiment Station, G. L. M.ACK. Geneva, New York. Aug. 3.

${ }^{1}$ Ahmad, Biochem. J., 29, 275 (1935).

${ }^{2}$ Ahmad, Nature, 136, 797 (1935).

a McHenry and Graham, Biochem. J., 29, 2013 (1935).

- Van Eekelen, NATURE, 136, 144 (1935).

${ }^{5}$ Siebert, Inaug. Dissertation, Frankfort a. Main (1931) ; Tillmans, Z. Unter. Lebensm., 68, 267 (1932).

${ }^{6}$ Guha and Pal, NATURE, 137, 946 (1936).

\section{Phosphagen in Echinoid Muscle and in Electrical Tissue}

Ir has been shown ${ }^{1,2}$ that the electrical organs of Torpedo contain phosphagen, thus adding another to the series of resemblances already known to exist between electrical and muscular tissue. The possibility that both tissues may make use of the same or similar chemical mechanisms led us to study the electrical cells of Torpedo from the point of view of the interrelationships of certain of the phosphorylated compounds believed to be concerned in muscle chemistry.

It was found that the partition of phosphorus in the tissue is very like that in the muscles of the rat and the frog, and the following observations all serve to confirm the close resemblance already men. tioned. (1) Extracts and breis prepared from the electrical organ will synthesize creatine phosphoric acid from creatine and phosphoglyceric or phosphopyruvic acid in the presence of adenylpyrophosphate or adenylic acid under conditions which lead to a similar synthesis in muscle preparations. (2) In dialyzed extracts this synthesis is catalyzed by the magnesium ion. (3) Phosphoglyceric acid is converted into pyruvic acid (demonstrated by the nitroprusside reaction and by the formation of a crystalline 2-4-dinitrophenylhydrazone). (4) Phosphagen can be synthesized from adenylpyrophosphate in high concentration without the addition of phosphoglyceric or phosphopyruvic acid. (5) Adenylpyrophosphate is rapidly dephosphorylated by such tissue preparations.

Hence this electrical tissue, like muscle, contains enzymes capable of catalyzing the following reactions :

(1) Phosphoglyceric acid $\rightarrow$ phosphopyruvic acid

(2) Phosphopyruvic acid + adenylic acid $\rightarrow$ adenyl pyrophosphate + pyruvic acid;

(3) Adenylpyrophosphate + creatine $\rightarrow$ adenylic acid + phosphagen ;

(4) Adenylpyrophosphate $\rightarrow$ adenylic acid + phosphoric acid.

It therefore seems very probable indeed that the cells of muscle and of the electrical organ of Torpedo alike derive the energy for their activity from the same chemical sources through the same chemical mechanisms, a suggestion which harmonizes with the well-known parallel between the physiological and pharmacological behaviour of the tissues in question, and the fact that they are both derived from embryonic pre-muscular rudiments.

Needham, Needham, Baldwin and Yudkin ${ }^{3}$ reported the presence in the jaw muscles of Paracentrotus of two phosphagens, believed to be the phosphoric acid compounds of creatine and arginine respectively. In view of the phylogenetic interest ${ }^{4}$ of these results we have studied the behaviour of certain phosphorylated compounds in the presence of enzyme extracts, prepared from the jaw muscles of Sphoprechinus granularis, and have been able to demonstrate the synthesis of two phosphagen-like compounds from creatine and arginine respectively. The first of these behaves exactly in the way expected of creatine phosphoric acid, and in view of the results already reported by Needham, Needham, Baldwin and Yudkin, is almost certainly that compound. The second, synthesized by the enzyme preparations from arginine, behaves, so far as we can determine, like arginine phosphoric acid. Its hydrolysis is considerably retarded by molybdate, and the base liberated by the hydrolysis gives the Sakaguchi reaction and, when submitted to the action of arginase prepared from rabbit liver, gives quantitative yields of urea.

All the evidence we have obtained confirms the existence in echinoid jaw muscle of enzymes analogous to, if not identical with, those found in the muscles of other organisms and, as reported above, in the electrical organ of Torpedo, and we have found no reason to suppose that the mechanisms involved in the synthesis of the two phosphagens differ essentially from those demonstrated in vertebrate muscle by the Parnas school $^{5}$ and Needham and van Heyningen ${ }^{6}$, and in arthropod muscle by Lehmann?

This confirmation of our earlier results makes us feel justified in laying considerably more emphasis than hitherto upon the phylogenetic significance of these purely biochemical results.

\section{ERNEST Baldwin.}

DoRothy MoYle NeEdham.

Station Maritime de Biologie,

Tamaris-sur-Mer,

Var, France.

August 15.

${ }^{1}$ Kisch, Biochem. Z., 225, 183 (1930).

${ }^{2}$ Baldwin, J. Exp. Biol., 10, 222 (1933).

3 Needham, Needham, Baldwin and Yudkin, Proc. Roy. Soc., B, 110, 260 (1932).

' Needham and Needham, Sci. Progress, 104, 626 (1932).

s Parnas, Ve Congres de Chimie Biologique, Bruxelles (1935).

- Needham and van Heyningen, NatuRE, 135, 585 (1935).

7 Lehmann, Biochem. Z., 281, 271 (1935).

\section{Swarming of the Males of Certain European Anophelines in Captivity}

THE study of the biology of the European Anopheles, particularly the complex of forms known as Anopheles maculipennis, has been greatly ham. pered by the difficulty of inducing mating under laboratory conditions. Missiroli and $\mathrm{I}^{1}$ have given a summary of the experiments made with these mosquitoes, of which only the 'race' known as atroparvus has mated in captivity. In this form, it appears that there is no sexual dance on the part of the males as a preliminary to mating. Curiously 